\title{
Educação intercultural em movimento: revisitando um conceito a partir do trabalho de investigação em grupo
}

\author{
Gilberto Ferreira da Silva* \\ Flor Ángeles Cabrera Rodríguez**
}

\section{Resumo}

O propósito deste trabalho é o de colocar como campo de discussão a produção de pesquisa ancorada no ambiente proporcionado pelo Grupo de Investigación en Educación Intercultural (GREDI) da Universidade de Barcelona. Centrou-se em conhecer o percurso da concepção de educação intercultural adotada nas pesquisas produzidas ao longo de 17 anos (1992-2009). Os intensos processos de imigração nestas últimas décadas e a consequente presença da diversidade cultural nos espaços educativos alimentam o esforço investigativo em conhecer e construir alternativas para o enfrentamento do fenômeno da multiculturalidade. Neste cenário a discussão pautada pela noção de educação intercultural tem estimulado uma crescente produção acadêmica, aportando contribuições, explorando modelos e projetos de intervenção em contextos educativos. Observase que o deslocamento de concepções simples da interculturalidade dá lugar a elaborações mais complexas e que apontam para interfaces interdisciplinares na consolidação de um campo de pesquisa.

Palavras-chave: Educação intercultural; Formação de professores; Grupo de pesquisa, diversidade cultural.

\section{Intercultural education in action: revisiting a concept from the group research}

\begin{abstract}
The purpose of this work is to place as field of discussion the research production anchored in the environment provided by the Grupo de Investigación en Educación Intercultural (GREDI), University of Barcelona. It focused on knowing the route of the conception of intercultural education adopted in the research produced over seventeen years (1992-2009). The intense process of immigration in recent decades and the consequent presence of cultural diversity in educational spaces feed the investigative effort to meet and build alternatives for coping with the phenomenon of multiculturalism. In this scenario the discussion guided by the
\end{abstract}

\footnotetext{
* Doutor em Educação, Bolsista CNPq. Professor do Programa de Mestrado em Educação e do Curso de Pedagogia do Unilasalle. Canoas, Rio Grande do Sul, Brasil.

** Investigadora del GREDI (Grupo de Investigación en Educación Intercultural). Universidade Autónoma de Barcelona, Espanha, Catedrática da Universidad de Barcelona - Departamento Métodos de Investigación y Diagnóstico en Educación (MIDE).
} 
concept of intercultural education have stimulated a growing academic production, bringing contributions, exploring models and intervention projects in educational settings. It is observed that the shift from simple concepts of interculturalism gives rise to more complex constructions and interfaces that point to consolidation in the interdisciplinary field of research.

Keywords: Intercultural education; Teacher training; Research group; Cultural diversity.

\section{Introdução}

O deslocamento de uma análise privilegiando as contribuições de um determinado grupo étnico-cultural para o enfrentamento da diversidade cultural mobilizou a realização desta pesquisa. As noções de multiculturalismo e interculturalidade ganham destaque. Esse deslocamento implicou um duplo movimento. De um lado, descortinou-se um universo teórico novo, fazendo emergir categorias analíticas desconhecidas. Conectados diretamente à formação docente, os conceitos de diversidade cultural, identidades étnicas, racismo e preconceito passam a ocupar um lugar privilegiado nas reflexões. As aspirações por compreender como é possível realizar processos formativos que contemplem o fenômeno da multiculturalidade sob a perspectiva da interculturalidade, impulsionam a busca por referências e experiências práticas que possam oferecer subsídios de forma mais objetiva ao tratamento deste fenômeno.

Este estudo insere-se neste cenário, onde, acima de tudo, o compromisso com práticas educativas críticas e transformadoras da realidade social são procuradas com o afã de quem acredita no papel da educação. O propósito deste trabalho coloca como campo de discussão a produção ancorada no ambiente proporcionado pelo Grupo de Investigación en Educación Intercultural (GREDI) da Universidade de Barcelona. Centrou-se em conhecer o percurso da concepção de educação intercultural adotada nos trabalhos produzidos. Portanto, na primeira parte, introduz-se uma apresentação sintética do GREDI, mapeiam-se as teses de doutorado defendidas no ambiente formativo do grupo e destacamse as contribuições no campo da trajetória das pesquisas produzidas, sob a perspectiva da educação intercultural.

Utilizou-se o acervo de teses disponível na biblioteca própria do GREDI e o sistema TDX (Tesis Doctorals en Xarxa) ${ }^{1}$ que permite o acesso virtual aos textos completos das teses defendidas nas universidades da comunidade autônoma da Catalunha. Ao acervo da Biblioteca da Faculdade de Educação (UB), recorreu-se com o propósito de averiguar e revisar a existência de algum trabaIho que pudesse não estar disponível em outros acervos. O período de buscas compreendeu 17 anos, ou seja, desde a criação do grupo em 1992 até novembro de 2009. 
Educação intercultural em movimento: revisitando um conceito a partir do trabalho de investigação em grupo

\section{Sobre o contexto em que a pesquisa se produziu}

O Grupo de Pesquisa em Educação Intercultural, ${ }^{2}$ vinculado ao Departamento - Métodos de Investigación y diagnóstico en Educación (MIDE-UB), iniciou suas atividades em 1992. Tem como foco central das preocupações investigativas a questão da diversidade cultural e étnica, procurando encontrar alternativas para os desafios enfrentados no campo da educação intercultural.

O GREDI mantém um vínculo estreito com a educação fundamental do sistema educativo espanhol, do qual vem se alimentando através de um rico processo de interlocução entre academia e escola. Outra preocupação do grupo passa pelo campo metodológico da produção da pesquisa procurando, pela combinação entre o quantitativo e o qualitativo, desenvolver experiências metodológicas no tratamento do fenômeno da diversidade cultural e étnica (SANDÍN ESTEBAN, 1997; SABARIEGO, 2001; MASSOT LAFFONT, 2001; FOLGUEIRAS, 2003, 2005). O grupo encontra-se, atualmente, organizado a partir de cinco linhas de pesquisa: Educação Intercultural; Identidade étnicocultural e educação; Gênero e educação; Cidadania Intercultural e Mediação e inclusão social.

Os estágios de membros do grupo em universidades estadunidenses e canadenses têm revelado o interesse e o potencial por levar adiante proposta de maior monte. Ainda que o grupo venha realizando essas atividades de cooperação internacional, vale destacar a preocupação e o compromisso com a educação fundamental, que podem ser verificados em seus documentos: “... nunca hemos olvidado que nuestra primera fuente de aprendizaje es la realidad y los educadores y educadoras comprometidos en el día a día con una tarea que, a veces, cuenta con muy pocos apoyos" (Página web GREDI).

Localizou-se um conjunto produzido de 14 teses no ambiente do GREDI, distribuído nas linhas de pesquisa da seguinte maneira: Educação Intercultural (4), Identidade étnico-racial (2), Gênero e Educação (0), Cidadania intercultural (2), Mediação e Inclusão Social (3) e outras três localizadas em diferentes campos. Observa-se, à primeira vista, para um leitor desatento, uma imagem que faz referência a um mosaico de cores e formas, aparentemente sem pontos que permitam vislumbrar uma proposta de trabalho sustentada em objetivos comuns. Entretanto, quando se examina os trabalhos, o mosaico ganha forma e pode, em um primeiro momento, ser sintetizado pelo compromisso político com a educação, traduzido no trabalho de investigação executado, o que torna a afirmação extraída da página web do grupo revelador dos propósitos, distanciando-se de uma retórica. Para dar conta de nosso objetivo, centramos nossa atenção na discussão que atravessa as diferentes investigações, destacando o processo de construção da concepção de educação intercultural. 


\section{Sobre a trajetória da noção de educação intercultural}

Analisando a evolução das investigações produzidas a partir de 1992, observa-se que os primeiros trabalhos, provavelmente gestados na fase que antecedeu a criação do grupo, apresentam uma discussão em que a noção de educação intercultural é praticamente inexistente. Esse é o caso da investigação realizada por Ramona González (1996) e Jaime Del Campo Sorribas (1998).

Outro aspecto a destacar refere-se ao fato de que os trabalhos contemplam, em sua grande maioria, uma aplicação prática de uma proposta que é acompanhada, analisada e avaliada. Em grande medida, os trabalhos exploram um programa de formação em que a aplicabilidade, aliada ao rigor científico e ao diálogo com as produções existentes no campo, são marcas próprias do trabaIho do GREDI.

O trabalho de Sandín Esteban, em 1997, inaugura o campo temático que vai constituir-se como preocupação central nos trabalhos subsequentes para o grupo. Como bem lembra a investigadora, é devido à sua inserção em trabalhos de investigação do grupo que emerge seu interesse por realizar uma pesquisa que coloca ênfase nos processos de construção identitária de grupos minoritários, em especial, adolescentes imigrantes. Em síntese, a pesquisadora explora em seu trabalho a compreensão das identidades étnicas quando postas em contato com outras formas culturais distintas. Quanto à compreensão sobre educação intercultural, a autora parte do pressuposto de que a multiculturalidade é um fato consumado na sociedade e, por tabela, no espaço escolar. Alude à necessidade de a escola assumir o desafio de ultrapassar a mera assimilação cultural dos grupos minoritários em sua ação:

[...] a multiculturalidade é um fato presente em nossa sociedade e em nossas aulas e, portanto, o sistema educativo não pode das às costas a esta realidade e deve propor o desafio de uma integração cultural das minorias na perspectiva não de uma mera assimilação, mas de enriquecimento mútuo das culturas majoritárias e minoritárias, como um princípio básico da interculturalidade. (SANDÍN ESTEBAN, 1997, p.131) ${ }^{4}$

Marta Sabariego (2001) toma como campo de conhecimento a formação inicial e permanente de professores, propondo um programa de formação de professores que atuam na educação secundária. Parte da ideia de que os atuais programas de formação inicial e permanente não dão conta de responder aos desafios apresentados pela diversidade cultural. Apoia-se, para isso, na perspectiva de uma educação intercultural. Contempla em sua pesquisa professores e estudantes de secundaria (Ensino Médio) . Em relação aos estudantes, explora a ideia de fomentar a identidade cultural; quanto aos educadores, trabalha na perspectiva do professor reflexivo. Constituem seu campo empírico de aplicação, avaliação e análise quatro Centros Educativos dos bairros da cidade de 
Barcelona: Ciutat Vella, el Raval, la Barceloneta e Sant Martí de Provençals (Distrito de Barcelona). Todos os locais escolhidos apresentam alto índice de imigração e são identificados pela própria autora, apoiada em dados estatísticos sobre imigração, como espaços "socialmente conflitivos e desfavorecidos". Durante a realização do programa de formação para os professores, o GREDI esteve envolvido no processo como grupo de pesquisa.

A partir de um rigoroso mapeamento da discussão sobre multiculturalismo e interculturalidade, a autora apresenta uma complexa rede de conceitos em que se move os autores, tanto no âmbito internacional quanto nacional. Demarca a opção por trabalhar com a perspectiva da interculturalidade, esclarecendo que falar de educação multicultural engloba os diferentes modelos de práticas educativas. No dizer da autora:

No marco de nosso trabalho consideraremos a distinção entre multiculturalismo e interculturalidade de acordo com os critérios que apresentam Bartolomé (1991) e Galino; Escribano (1990), falaremos de educação multicultural somente quando nos referirmos aos diferentes modelos ou paradigmas de intervenção que foram construídos para atuar em uma sociedade caracterizada pela coexistência de diferentes grupos culturais. (SABARIEGO, 2001, p. 52) ${ }^{5}$

Nesse sentido, o trabalho de Sabariego apresenta uma característica importante ao estabelecer conexões entre a educação intercultural e outras filosofias educativas, tais como a educação pelos direitos humanos e a educação para o desenvolvimento. Afirma o quanto os vínculos entre essas perspectivas são estreitos, pois compreende a educação intercultural como um compromisso com a construção de uma sociedade, em que o diálogo e a alteridade constituem-se como princípios orientativos (SABARIEGO, 2001).

Maria Inés Massot Laffont (2001), de nacionalidade argentina, talvez por sua própria condição de imigrante, desenvolve um estudo sobre o processo de construção identitária étnica dos filhos e filhas de imigrantes argentinos e uruguaios estabelecidos na Catalunha. Os sujeitos da pesquisa são jovens entre 17 e 22 anos. Procura construir "un modelo que refleje el sentimiento de pertenencia de estos jóvenes" (p.155). A discussão sobre a identidade étnicacultural de jovens é incrementada, dando abertura para a análise dos fenômenos culturais no âmbito juvenil, a exemplo do que anteriormente havia sido explorado por Sandín (1997).

Massot Laffont (2001) situa seu trabalho a partir da constatação que a multiculturalidade é um fato intensificado nas últimas décadas pela imigração do Terceiro Mundo. Tal cenário gerou a necessidade de construir alternativas para compreender as múltiplas inter-relações entre os grupos minoritários e as sociedade receptoras, de igual maneira, afirma a autora, a escola assume um 
papel primordial como difusora e transmissora de padrões culturais. A pesquisadora circula livremente por uma vasta bibliografia, discutindo temas como raça, etnia, identidade latino-americana, imigração do Terceiro Mundo etc., aportes importantes para se construir perspectivas para a atuação docente e para a tarefa institucional da escola em espaços multiculturais, acepção tão bem distinguida por Sabariego (2001). As temáticas que constituem nosso objeto de estudo neste trabalho não ganham aportes explícitos, ainda que façam parte das diferentes sensibilidades pós-coloniais, conforme sugerem Canen, Arbache e Franco (2000). Tais sensibilidades têm permitido ampliar a compreensão de temáticas constituintes do fenômeno da multiculturalidade e, no caso da pesquisa de Massot, reforça a necessidade da compreensão sobre os processos de constituição de identidades culturais, já não mais aprisionadas a visões estáticas e rígidas, mas produzidas em espaços plurais.

A proposta em trabalhar com competências interculturais em empresas multiculturais, enfocando aspectos no campo da formação de recursos humanos é a plataforma em que se movimenta Maria Assunción Aneas Alvarez (2003) ao construir sua investigação. Este é um dos trabalhos que, de forma contundente, assume e preconiza a proposta geral, posta em andamento como projeto de trabalho do GREDI. Citando Bartolomé, Sandín y Del Campo (2002 apud ANEAS ALVAREZ, 2003, p. III, Introducción) expõe sua compreensão de educação intercultural:

\begin{abstract}
A educação intercultural não pode limitar-se à escola. Os problemas que nela se dão têm suas raízes nas dinâmicas em que vive a população e é necessária uma ação conjunta entre escola e comunidade para sua superação. Faz-se necessário ampliar o processo, buscando um nível de comprometimento de caráter institucional e social mais amplo. $(\ldots)^{6}$
\end{abstract}

É interessante destacar que, para Sandín (1997), o alerta centrava-se em compreender a educação intercultural como superação de atitudes e práticas assimilacionistas no espaço escolar. Para Aneas Alvarez, é necessária articulação entre comunidade e escola no enfrentamento da diversidade cultural. Propõe, em síntese, o compromisso da sociedade com essa realidade. Ele o faz de forma extremamente coerente com a defesa desse compromisso, aportando elementos desde o espaço da sociedade mais ampla, no caso, uma empresa de composição multicultural.

Virgínia Aranda Parra (2003) realiza um estudo sobre "choque cultural" com estudantes latinos de diferentes países, nos programas de doutorado da UB (Universidade de Barcelona). O objeto de estudo e a análise centram-se em dar conta dos processos objetivos e subjetivos de adaptação vividos pelos estudantes. Um trabalho que pode ser aproximado à ideia de uma sociologia da cultura e psicologia da cultura. Destaca que atitudes e valores são elementos 
para uma reconceptualização da ideia de choque cultural, assim como detecta que falhas na comunicação que priorizam a perspectiva da interculturalidade apontam para a necessidade de se pensar o choque cultural, não somente como uma categoria, mas como uma experiência social.

Francisco Javier de Santos Velasco (2004), a exemplo de Aneas Alvarez (2003), demonstra em seu trabalho encontrar um apoio teórico consolidado por parte da produção do grupo. Estuda o desenvolvimento das competências interculturais na gestão de empresas multiculturais, tomando como campo empírico a perspectiva de estudantes universitários. Centra-se em verificar como a universidade vem respondendo aos desafios da formação para essa realidade. Santos Velasco parte de uma concepção ampla sobre a noção de "intercultural", valorizando as interações entre pessoas de diferentes culturas, tendo como horizonte o diálogo e a negociação. A compreensão da cultura do outro se constitui como elemento fundamental para a compreensão da própria cultura.

O pesquisador alia uma característica que tem sido inerente ao conceito de educação intercultural na literatura internacional. Ou seja, a interculturalidade demarcada pela ação-intervenção em contexto multiculturais, ou ainda como proposta política comprometida com um projeto (MOREIRA, 2001; CANEN; ARBACHE; FRANCO, 2000; FLEURI, 2006; MCLAREN, 1997; SALINAS; NUÑEZ, 2001). "A interculturalidade é uma proposta de interpretação da vida social que coloca ênfase no respeito e no direito a diferença, que denuncia as visões essencialistas que em nome da cultura justificam a xenofobia, o racismo, a marginalização e a exclusão social" (SANTOS VELASCO, p. 7). ${ }^{7}$ Apoiando-se em pesquisadores do próprio GREDI e em outros, arremata sua compreensão afirmando que a aposta nas relações assume preponderância, muito mais do que o investimento nas diferenças entre culturas.

O que é possível observar até o momento é um conceito em permanente e dinâmico processo de construção e reconstrução. As aportações são feitas no sentido cumulativo, por vezes ampliando, por outras explicando. A noção de continuidade no processo de construção teórica é algo que se faz presente de forma objetiva nos trabalhos até aqui analisados. Há uma preocupação em garantir o avanço da discussão a partir de processos de implementação prática e de clareza teórica. As combinações e arranjos teóricos realizados pelos pesquisadores-educadores vão sendo tecidas em continuidade, demonstrando uma afinidade teórica e, com isso, revelando o quanto o trabalho coletivo na pesquisa em educação pode ser estimulante, tanto para os pesquisadores quanto para o avanço das compreensões sobre o objeto de estudo tomado como centralidade. Além disso, a diversidade de enfoques e abordagens particulares que compõe o fenômeno da diversidade cultural vai sendo complexificada, a exemplo do que sugere Barba (2006), incorporando dimensões como as questões das relações entre jovens e as de gênero, entre outras. Esta autora alude a ideia de se começar a tratar a interculturalidade no campo das mediações virtuais, a qual denomina de internetuality. 


\title{
Gilberto F. da Silva - Flor Ángeles C. Rodríguez
}

Mobilizada pela pergunta "que competências comunicativas interculturais são necessárias no primeiro ciclo da ESO (Educação Secundária Obrigatória)", Ruth Vilà Baños (2005) faz uma imersão na educação secundária, propondo um programa de intervenção que permita favorecer e desenvolver competências interculturais. Sobre a compreensão de educação intercultural, a pesquisadora analisa o contexto da discussão atual, apoiada na literatura nacional (Espanha) e internacional, principalmente anglo-saxônica. Aponta para as críticas que a educação intercultural tem sofrido nestas últimas décadas e afirma as bases em que a proposta se sustenta:

\begin{abstract}
Superar estas críticas sem renunciar a essência da educação intercultural, supõe assumir duas responsabilidades (Bartolomé, Cabrera, Espín, Marin y Rodriguez, 1999): a luta contra toda forma de exclusão social e o desenvolvimento de estratégias educativas que favoreçam valores compartilhados, a participação em um projeto comum e a construção de um espaço social integrador. (p. 4) ${ }^{8}$
\end{abstract}

Pilar Folgueiras (2005), preocupada com a formação para a cidadania ativa e intercultural, propõe um programa voltado à realidade de mulheres imigrantes em uma comunidade da região metropolitana de Barcelona (L'Hospitalet de Llobregat). Apoiada no modelo de formação para a cidadania, defendido pelo GREDI, a autora explora o fenômeno da diversidade cultural colocando ênfase na participação cidadã. Apresenta como pressuposto para desenvolver sua investigação a noção de educação intercultural voltada para uma simetria cultural, e assim como os investigadores anteriores, enfatiza o papel do diálogo para a construção de um projeto de sociedade que respeite as diferenças e estimule a solidariedade entre os coletivos portadores de culturas diferentes.

Desde uma perspectiva de educação extraescolar, ou ainda, de uma educação informal, Pilar Folgueiras amplia o escopo em que se movimentam as pesquisas produzidas e orientadas no ambiente investigativo do GREDI. Constata-se a diversidade das temáticas, já anunciadas anteriormente, assim como um processo de aperfeiçoamento e extensão da compreensão com que o grupo, dinamicamente, vai se constituindo no campo teórico para enfrentar o fenômeno da multiculturalidade, desde a perspectiva da educação. Por diferentes campos, constitui um olhar orgânico e articulado, tanto dos referenciais teóricos que subsidiam as reflexões até uma proposta delimitada cuidadosamente no campo das aplicações práticas daquilo que se produz intelectualmente. Dessa forma revelando, igualmente, o compromisso com a ação educativa carregada de sentido para o próprio fazer em educação.

Fronteiras disciplinares não são consideradas pelos pesquisadores para dar conta das múltiplas e dinâmicas interfaces que se movimentam no terreno das práticas socioculturais. Contribuições oriundas da antropologia, sociologia, história e filosofia são articuladas, mobilizadas pelo espírito inquiridor, próprio do investigador. 
Educação intercultural em movimento: revisitando um conceito a partir do trabalho de investigação em grupo

Iván Manuel Sánchez Montalvo, em pesquisa realizada em 2006, se propôs a analisar as necessidades formativas de professores de educação secundária atuantes em realidades multiculturais. Propõe um programa de formação que potencialize as dimensões da cidadania democrática intercultural na Colômbia. Como extensão do que já foi produzido pelo grupo de pesquisa, Sánchez Montalvo apresenta um quadro elucidativo das distinções entre as concepções de multiculturalismo e interculturalidade, o qual reproduzimos a seguir.

Paralelo Multiculturalismo e inerculturalidad. (SÁNCHEZ MONTALVO, 2006, p. 116)9

\begin{tabular}{|c|c|}
\hline Multiculturalismo & Interculturalidade \\
\hline $\begin{array}{l}\text { - Busca produzir e produz sociedades } \\
\text { paralelas }\end{array}$ & $\begin{array}{l}\text { - Busca produzir sociedades integradas } \\
\text { e relações simétricas entre as diversas } \\
\text { culturas }\end{array}$ \\
\hline $\begin{array}{l}\text { - O lema do multiculturalismo é: apesar } \\
\text { de sermos diferentes temos que } \\
\text { aprender a conviver sem agredir-nos, } \\
\text { quer dizer respeitando-nos }\end{array}$ & $\begin{array}{l}\text { - O lema da interculturalidade é: somos } \\
\text { iguais e diferentes. Aprendamos a } \\
\text { conviver enriquecendo-nos } \\
\text { reciprocamente }\end{array}$ \\
\hline $\begin{array}{l}\text { - As políticas multiculturais evitam os } \\
\text { conflitos }\end{array}$ & $\begin{array}{l}\text { - As políticas interculturais promovem } \\
\text { os encontros }\end{array}$ \\
\hline - Promove a tolerância & - Promove o diálogo \\
\hline $\begin{array}{l}\text { - Não erradica os estereótipos e os } \\
\text { preconceitos que contaminam as } \\
\text { relações entre as pessoas diferentes }\end{array}$ & $\begin{array}{l}\text { - Busca erradicar os preconceitos que } \\
\text { estão na base da estigmatização social } \\
\text { e da discriminação cultural }\end{array}$ \\
\hline $\begin{array}{l}\text { - As políticas multiculturais são ações } \\
\text { afirmativas }\end{array}$ & $\begin{array}{l}\text { - As políticas interculturais são ações } \\
\text { transformadoras, quer dizer, buscam } \\
\text { transformar as relações de } \\
\text { interculturalidade negativa em } \\
\text { interculturalidade positiva }\end{array}$ \\
\hline $\begin{array}{l}\text { - A racionalidade multicultural é uma } \\
\text { racionalidade monológica, não } \\
\text { reconhece ao outro como interlocutor } \\
\text { válido. }\end{array}$ & $\begin{array}{l}\text { - A racionalidade intercultural é } \\
\text { comunicativa que parte do } \\
\text { reconhecimento do outro interlocutor } \\
\text { com quem compartilho em situação de } \\
\text { dialogo uma comunidade de valores } \\
\text { transculturais. }\end{array}$ \\
\hline
\end{tabular}




\section{Gilberto F. da Silva - Flor Ángeles C. Rodríguez}

Considerando, principalmente, o quadro referente à caracterização da interculturalidade, podemos constatar os acréscimos que foram produzidos, indicando o processo da compreensão sobre educação intercultural, pois, ao construir a síntese pelo paralelismo em relação ao multiculturalismo, Sánchez Montalvo permite contemplar um conjunto de elementos aportado, em outras investigações do grupo, dos quais destacamos:

a) as políticas interculturais que possibilitem e estimulem o diálogo e o encontro entre pessoas de diferentes culturas que, por sua vez, através de

b) uma racionalidade intercultural sejam capazes de valorizar e reconhecer comunidades transculturais, a partir de uma postura aberta ao ato comunicativo.

Olga González Mediel (2008), tomando por princípio básico da educação intercultural o diálogo, apresenta sua intenção de pesquisa partindo da hipótese de que não se pode estabelecer o diálogo intercultural, se não se oferece aos alunos a possibilidade de conhecer outras manifestações culturais que permitam o reconhecimento e a valorização de sua própria cultura. Essa pesquisa é realizada em escolas públicas de um bairro da cidade de El Prat de Llobregat, que faz parte da região metropolitana de Barcelona. Além disso, coloca como preocupação a discussão sobre um currículo intercultural, utilizando-se da música como recurso para potencializar o diálogo entre culturas diferentes, a partir de um trabalho de pesquisa-ação com os educadores atuantes no centro educativo. A autora reforça a compreensão sobre educação intercultural até então adotada pelo GREDI:

Porém o termo "intercultural" já expressa a opção de colocar em contato, desde a tarefa educativa. Constitui um enfoque, um procedimento, um processo dinâmico de natureza social, na qual se impulsiona positivamente aos participantes a tomar consciência de sua interdependência e é também uma filosofia, uma política e um pensamento que sistematiza a realidade. (p.81$82)^{10}$

Para termos uma visão mais clara do processo que se verificou nas produções do GREDI, a partir do processo de construção e reconstrução do conceito e ou compreensão de educação intercultural, propomos a figura a seguir como forma didática, permitindo uma visão de conjunto do processo. 
Educação intercultural em movimento: revisitando um conceito a partir do trabalho de investigação em grupo

Figura 1 - Aportes em processo: Educação Intercultural

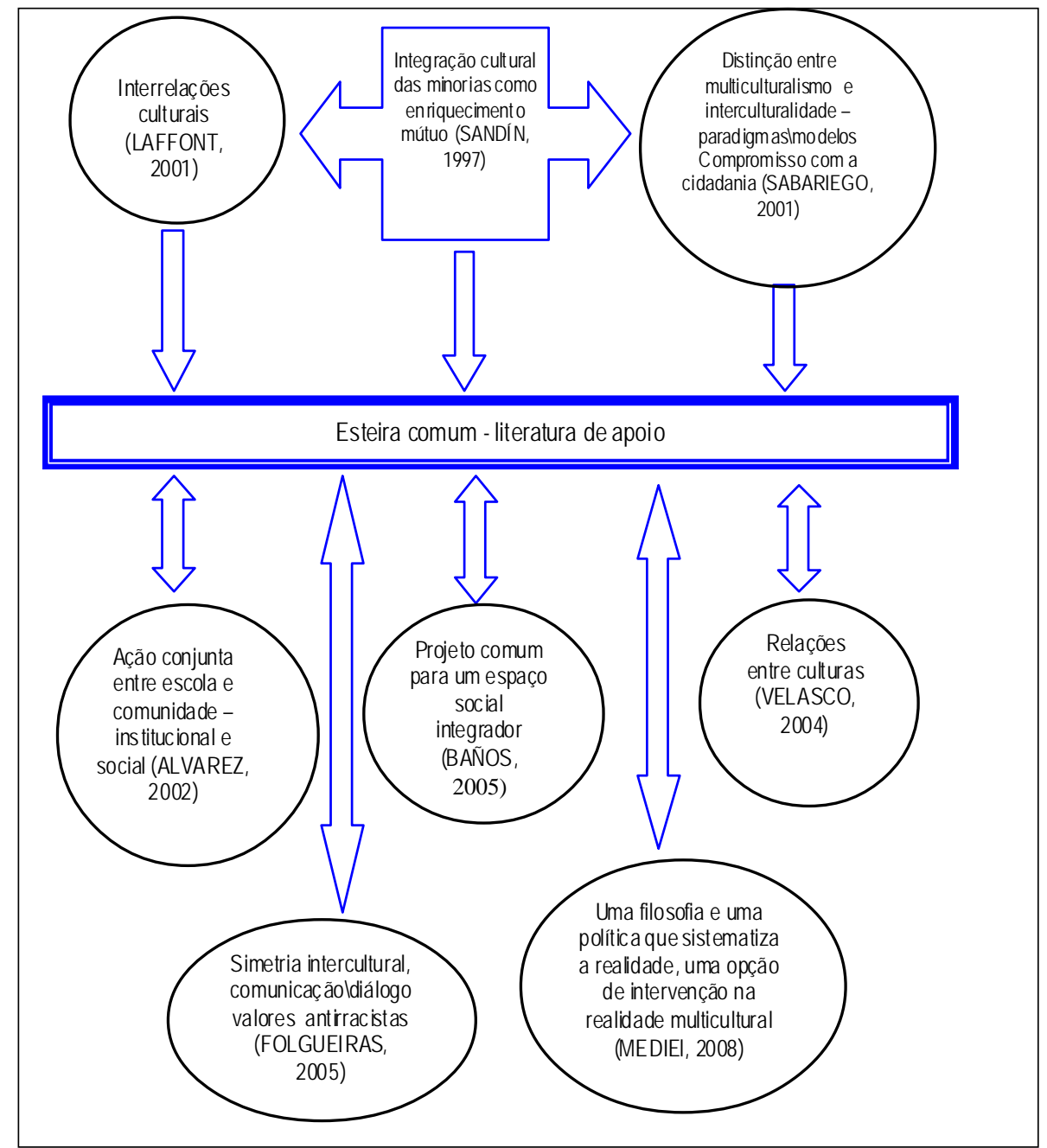

Pode-se dizer que alguns pressupostos sustentam a formulação da compreensão de educação intercultural, um deles sintetizado por Cabrera (2002) ${ }^{3}$ quando diz: "A cidade multicultural já não se baseia em um único poder de cultura autóctone. Todos os homens e mulheres são cidadãos. Por isso, um projeto educativo que promova a participação cidadã e o respeito mútuo terá que ser por definição intercultural". (p. 81) ${ }^{12}$

Ainda que se corra o risco de simplificar, é importante demarcar um ponto de referência para nossa reflexão. Bartolomé (2002) compreende a educa- 
ção intercultural como resposta à diversidade cultural existente, demarcada por uma clara opção pelo diálogo e pelas trocas culturais, tal dinâmica prevendo a contribuição efetiva da educação para o processo de transformação da sociedade.

Maria Paz Sandín Esteban (1997) reforça essa ideia em seu trabalho, quando afirma: "A educação intercultural produz a transformação do sujeito quando a referência para a comunicação é compartilhada e existe a vontade de conhecimento e compreensão do outro; se não existe, o diálogo intercultural é inexistente." (p. 507) ${ }^{13}$

Marta Sabariego (2001), partindo desse princípio, explica o papel da educação intercultural:

\begin{abstract}
$\mathrm{Na}$ medida que os referentes da interculturalidade temos de procurar nas praticas sociais e culturais das minorias, um elemento chave é desenvolver toda a potencialidade da educação intercultural desde uma concepção mais crítica da teoria e prática que centre a sua atenção, não se limitando ao tratamento implicitamente patológico e compensatório da diversidade cultural em prol do sucesso acadêmico das minorias, senão colocando a ênfase nas questões estruturais mais amplas do racismo e na preocupação de como educar a todo alunado, tanto os que procedem da maioria como os de grupos social e culturais minoritários, por uma sociedade multicultural. (p. 664) $)^{14}$
\end{abstract}

Massot Laffont (2001) advoga uma pedagogia da inclusão, acrescentando a necessidade de se desenvolver competências pluriculturais que dotem os jovens de referencias intelectuais para a reflexão crítica, para a responsabilidade e para a justiça social.

Utilizando da noção de competências interculturais, Aneas Álvarez (2003) procura dar continuidade à reflexão iniciada por Massot: "As competências Interculturais podem ser recursos valiosos para as pessoas da sociedade de acolhida: cidadania, profissionais, políticos ..." (p. 494). ${ }^{15} \mathrm{~A}$ autora exemplifica como se traduzem essas competências no cotidiano social aludindo a uma base sólida de conhecimentos, habilidades e atitudes, possibilitando construir relações baseadas na perspectiva intercultural.

Ruth Vilà Baños (2005), preocupada com a perspectiva de uma comunicação sustentada pela interculturalidade, vai propor um tipo de competência intercultural voltada ao ato comunicativo, afirmando ser este um dos aspectos importantes para se pensar as relações entre portadores de culturas diferentes. A autora afirma: "Melhorar as relações interculturais incide na convivência e coesão social, desde a simetria, desde a participação social, desde a igualdade de direitos, e também desde a diferença cultural e o respeito" (p. 665). ${ }^{16}$ 
Na busca por uma síntese do exposto, observa-se que a educação intercultural constitui-se como projeto de intervenção. Carrega em sua essência uma intencionalidade, tem por base o exercício do diálogo, problematizado na perspectiva da competência comunicativa intercultural, valorizando práticas de intercâmbio e enriquecimento mútuo entre portadores-produtores de culturas diferentes e uma clara opção de intervenção na sociedade, com vistas à transformação. Ganha ênfase a incidência sobre processos formadores que fomentem o exercício de uma cidadania intercultural, tanto para professores quanto para estudantes. As relações entre os espaços educativos e outros segmentos da sociedade, tais como a comunidade, a família e as organizações populares são mecanismos dinâmicos, nos quais uma educação pautada pelos princípios da interculturalidade encontra canais de revitalização e sentido de sua proposta.

Por outro lado, podemos dizer que a educação intercultural atualiza uma proposta de educação já anunciada pela educação popular nos anos 60, delegando um lugar privilegiado para a diversidade cultural, em conformidade com os atuais movimentos de circulação de bens culturais pelas mais diversas regiões do planeta.

Entretanto, duas questões que queremos problematizar, como resultado final desta análise, referem-se ao que denominamos de dimensões. Uma primeira, de caráter mais teórico e outra de caráter pragmático. Na primeira dimensão está justamente um dos elementos considerados fundamentais para a concretização de uma educação na perspectiva da interculturalidade, ou seja, o diálogo intercultural. É preciso considerar a complexidade que reveste esta premissa que tem sido uma unanimidade nos discursos sobre interculturalidade para além dos trabalhos já citados (DÍEZ, 2004; SILVA, 2004; LÓPEZ, 2001; HOPENHAYN, 2009). Nesse sentido se perguntar pelas condições em que o diálogo intercultural se produz se coloca como um ponto de partida. Seria possível o diálogo entre sujeitos portadores-produtores de culturas diferentes, uma vez que se encontram em uma relação de desigualdade? Estas condições que são marcadas por processos históricos, sociais e mesmo culturais podem ser ultrapassadas através de práticas que estimulem a participação, o respeito, a solidariedade e todo o conjunto de valores apregoados pela educação intercultural? A proposição de Ruth Vilá Baños (2005), ao enfatizar a competência comunicativa como um aspecto emergente e vital para a consolidação do projeto intercultural nos oferece algumas pistas, ainda que insuficientes.

Na segunda dimensão, está a preocupação com a estrutura curricular que deve responder aos desafios da educação intercultural, pois compreendemos que para traduzir de forma pragmática as proposições e princípios da educação intercultural no campo da educação formal, por exemplo, é preciso repensar, questionar e reestruturar o projeto curricular. Seguindo o que defende Moreira (2001), compreendemos por currículo os planos que orientam o fazer educativo desde uma forma ampla no âmbito da instituição educativa até as práticas cotidianas desenvolvidas pelos educadores no seu quefazer pedagógico em torno 
do conhecimento escolar. Observa-se, neste aspecto, a necessidade de investimento investigativo que explore formas alternativas de organizar o currículo, assim como estudos que enfatizem e revelem como estão ocorrendo as práticas que se propõem a valorizar a diversidade cultural a partir de seus projetos pedagógicos. Caminhos que terão que ser trilhados.

\section{Conclusão}

Ao finalizar este trabalho, retomamos alguns aspectos do percurso de investigação levado a cabo no ambiente do GREDI, a partir de duas dimensões. A primeira refere-se ao percurso da construção da ideia de educação intercultural. Procuramos demonstrar como foi se constituindo a discussão teórica sobre educação intercultural e como foi se deslocando das primeiras concepções, em que se advogava a ideia de culturas em contato em um mesmo espaço, para noções ampliadas, incorporando contribuições de diferentes campos do conhecimento. Em síntese, os trabalhos revelam a interculturalidade, compreendida como um projeto de sociedade em construção, no qual as pessoas se reconhecem a si mesmas e estabelecem o diálogo, valorizando as diferenças e os conflitos daí gerados. Igualmente a interculturalidade nutre-se de perspectivas interdisciplinares para tratar do fenômeno da diversidade cultural. A compreensão de interculturalidade que se defende aposta em mudanças desde o campo da educação visando a construção de um projeto de sociedade que reconheça e valorize a todos.

A segunda dimensão aponta para a importância do trabalho em grupo de pesquisa, oferecendo elementos para uma remodelagem do papel que esses ambientes podem oferecer para a qualificação da pesquisa em educação. As inter-relações entre os trabalhos produzidos, primando pela continuidade e pelo aprofundamento das noções são inerentes às pesquisas produzidas, explicitando a dinâmica e reforçando o significado do trabalho em grupo. Evidencia-se que as teses são produzidas com a participação efetiva, e por que não dizer também afetivas de outros pesquisadores do grupo, somando-se e contribuindo para a realização de um trabalho que traduz o compromisso com a produção do conhecimento e com a transformação das práticas educativas. Uma das evidências localiza-se na proposição de programas de formação em que é possível diagnosticar, desenvolver, acompanhar, problematizar e avaliar, compondo uma metodologia sustentada nos princípios da pesquisa-ação colaborativa.

\section{Referências}

BARBA, C. C. Diversidad cultural y nociones relacionadas: un análisis conceptual. In: MEJÍA-ARAUZ, R.; RIVERA, H.; FRISANCHO, S. (Coords.). Investigar la diversidad cultural. Teoría, conceptos y métodos de investigación para la educación y el desarrollo. México, Universidad de Colima, Universidad Iberoamericana, ITESO, 2006. p. 15-43. 
BARTOLOMÉ, M. Educar para una ciudadanía intercultural. In: BARTOLOMÉ, $M$. (Coord.). Identidade y ciudadanía. Un reto a la educación intercultural. Narcea: Barcelona, 2002. p. 131-161.

BERTOMEU, P. F. De la tolerancia al reconocimiento mutuo: Programa de formación para una ciudadanía activa. Encounters on Education. Vol. 4, p. 2746, Fall, 2003.

CABRERA, F. A. Hacia una nueva concepción de la ciudadanía en una sociedad multicultural. In: BARTOLOMÉ, M. (Coord.). Identidade y ciudadanía. Un reto a la educación intercultural. Narcea: Barcelona, 2002. p.79-104.

CABRERA, F. A. Hacia una nueva concepción de la ciudadanía en una sociedad multicultural. IN: BARTOLOMÉ, M. (Coord.). Identidad y ciudadanía. Madrid: Narcea, 2002.

CANEN, A.; ARBACHE, A. P.; FRANCO, M. Pesquisando multiculturalismo e educação: o que dizem as dissertações e teses. Trabalho apresentado na XXIII Reunião Anual da ANPEd, Caxambu, MG, 2000.

DÍEZ, M. L. Reflexiones en torno a la interculturalidad. Cuadernos de Antropología Social. N. 19, pp. 191-213, 2004. Disponível em: http:// www.scielo.org.ar/pdf/cas/n19/n19a12.pdf Acesso em: 01 jan. 2010.

FLEURI, R. M. (Org.). Educação intercultural: mediações necessárias. Rio de Janeiro: DP\&A, 2003a. 23, pp. 16-35.

Intercultura e educação. Revista Brasileira de Educação. 2003b, n.

HOPENHAYN, M. La educación intercultural: entre la igualdad y la diferencia. Pensamiento Iberoamericano. n. 4, p. 49-71, Segunda Época, 2009., Disponível em: http://www.pensamientoiberoamericano.org/articulos/4/95/0/laeducacion-intercultural-entre-la-igualdad-y-la-diferencia.html. Acesso em: 06 dez. 2009.

LÓPEZ, L. E. La Cuestión de la Interculturalidad y la Educación Latinoamericana. Séptima Reunión del ED-01/ PROMEDLAC VII/ Comité Regional Intergubernamental del Proyecto Principal de Educación en América Latina y el Caribe, Documento de Apoyo, UNESCO, 2001. 21p. disponible em http://www.ifejants.org/aulavirtual2/uploaddata/2/UNI_2/interculturalidad.pdf. Acesso em: 01 jan. 2010.

MCLAREN, P. Multiculturalismo crítico. São Paulo: Cortez, 1997.

MOREIRA, A. F. B. A recente produção científica sobre currículo e multiculturalismo no Brasil (1995-2000):avanços, desafios e tensões. Revista Brasileira de Educação. set., out., nov., dez., n. 18, p. 65-81, 2001. 
Gilberto F. da Silva - Flor Ángeles C. Rodríguez

SALINAS, S. C. Interculturalidad, educación y política em América Latina. Revista Política y Cultura, número 17, Universidad Autónoma Metropolitana Xochimilco, Distrito Federal, México. 2002. p. 261-288.

SILVA, G. F. Sociedade Multicultural: educação, identidade(s) e culturas(s). Educação (PUC/RS), Porto Alegre, v. 2, n. 53, p. 283-302, 2004.

Teses

ANEAS ÁLVAREZ, M. A. Competencias interculturales transversales en la empresa: un modelo para la detección de necesidades formativas. Tese de Doutorado. MIDE - Universidade de Barcelona. Barcelona, 2003.

ARANDA PARRA, V. Modelo de choque cultural y propuesta educativa: una investigación con alumnado latinoamericano de tercer ciclo de la Universidad de Barcelona. Tese de Doutorado. MIDE - Universidade de Barcelona. Barcelona, 2003.

DEL CAMPO, J. Los centros cerrados de menores: entre la educación y el control. Evaluación de un caso. Tese de Doutorado. MIDE - Universidade de Barcelona. Barcelona, 1998.

FOLGUEIRAS, P. De la tolerancia al reconocimiento: Programa de formación para una ciudadanía intercultural. Tese de Doutorado. MIDE Universidade de Barcelona. Barcelona, 2005.

GONZÁLEZ I SOLER, R. La iniciación en la escuela del maestro novel. Tese de Doutorado. MIDE - Universidade de Barcelona. Barcelona, 1996.

GONZÁLEZ MEDIEL, O. Cap a un currículum intercultural a Primària. La investigació-acció com a metodologia i la cançó com a desencadenant del canvi. Tese de Doutorado. MIDE - Universidade de Barcelona. Barcelona, 2008.

MASSOT LAFFONT, M. I. Vivir entre dos culturas. Tese de Doutorado MIDE Universidade de Barcelona, Barcelona, 2001.

SABARIEGO, M. L'educación intercultural a la secundària obligatòria: investigación avaluativa. Tese de Doutorado. MIDE - Universidade de BarceIona, Barcelona, 2001.

SÁNCHEZ MONTALVO, I. M. Educación para una ciudadanía democrática e intercultural en Colombia. Tese de Doutorado. MIDE - Universidade de Barcelona. Barcelona, 2006.

SANDíN, M. P. Desarrollo de la identidad étnica en adolescentes desde una perspectiva intercultural: evaluación participativa de un programa de acción tutorial. Tese de Doutorado. MIDE - Universidade de Barcelona. Barcelona, 1997. 
Educação intercultural em movimento: revisitando um conceito a partir do trabalho de investigação em grupo

SANTOS VELASCO, F. J. de. Desarrollo de la competencia intercultural en alumnado universitario: una propuesta formativa para la gestión de empresas multiculturales. Tese de Doutorado. MIDE - Universidade de Barcelona. Barcelona, 2004.

VILÀ BAÑOS, R. La Competencia Comunicativa Intercultural: un estudio en el primer ciclo de la ESO. Tese de Doutorado. MIDE - Universidade de BarceIona. Barcelona, 2005.

Notas

1 Endereço eletrônico: http://www.tesisenxarxa.net/. Acesso em: 01 nov. 2009.

2 Endereço eletrônico: http://www.gredi.net/web/index. Acesso em: 01 nov. 2009.

3 Tanto Flor Ángeles Cabrera quanto Margarita Bartolomé são pesquisadoras, orientadoras das teses de doutorado do grupo e fundadoras do GREDI.

${ }^{4}$ [...] la multiculturalidad es un hecho presente en nuestra sociedad y en nuestras aulas y, por tanto, el sistema educativo no puede dar la espalda a esta realidad y debe plantearse el reto de una integración cultural de las minorías en la perspectiva no de la mera asimilación, sino de un enriquecimiento mutuo de las culturas mayoritarias y minoritarias, como un principio básico de la interculturalidad (SANDÍN ESTEBAN, 1997, p. 131).

${ }^{5}$ En el marc del nostre treball considerarem aquesta distinció entre multiculturalisme i interculturalitat, id'acord amb el criteri que assenyalen Bartolomé (1991) i Galino i Escribano (1990) únicament parlarem d'educació multicultural quan ens referim als diferents models o paradigmes d'intervenció educativa que s'han dissenyat per actuar en una societat caracteritzada per la coexistencia de diversos grups culturals (SABARIEGO, 2001, p. 52).

${ }^{6}$ La educación intercultural no puede circunscribirse a la escuela. Los problemas que en ella se dan tienen sus raíces en las dinámicas que vive la población y es necesaria una acción conjunta escuela comunidad par a su superación. Se hace necesario ampliar el proceso, buscando un nivel de implicación de carácter institucional y social más amplio (...).

7 "La interculturalidad es una propuesta de interpretación de la vida social que pone énfasis en el respeto y el derecho a la diferencia y que denuncia las visiones esencialistas, que en nombre de la cultura justifican la xenofobia, el racismo, la marginación y la exclusión social" (p. 7), diz o autor.

${ }^{8}$ Superar estas críticas sin renunciar a la esencia de la educación intercultural, supone asumir dos responsabilidades (Bartolomé, Cabrera, Espín, Marín, y Rodríguez, 1999): la lucha contra toda forma de exclusión social y el desarrollo de estrategias educativas que favorezcan valores compartidos, la participación en un proyecto común, y la construcción de un espacio social integrador. (VILÀ BAÑOS, 2005, p. 4) 
Gilberto F. da Silva - Flor Ángeles C. Rodríguez

\begin{tabular}{|c|c|}
\hline Multiculturalismo & Interculturalidad \\
\hline $\begin{array}{l}\text { - Busca producir y produce sociedades } \\
\text { paralelas }\end{array}$ & $\begin{array}{l}\text { - Busca producir sociedades integradas } \\
\text { y relaciones simétricas entre las } \\
\text { diversas culturas }\end{array}$ \\
\hline $\begin{array}{l}\text { - El tema de la interculturalidade es: a } \\
\text { buena hora somos iguales y diferentes. } \\
\text { Aprendamos a convivir } \\
\text { enriqueciéndonos recíprocamente }\end{array}$ & $\begin{array}{l}\text { - El tema de la interculturalidade es: a } \\
\text { buena hora somos iguales y diferentes. } \\
\text { Aprendamos a convivir } \\
\text { enriqueciéndonos recíprocamente }\end{array}$ \\
\hline $\begin{array}{l}\text { - Las políticas interculturales promueven } \\
\text { los encuentros }\end{array}$ & $\begin{array}{l}\text { - Las políticas interculturales promueven } \\
\text { los encuentros }\end{array}$ \\
\hline - Promueve el dialogo & - Promueve el dialogo \\
\hline $\begin{array}{l}\text { - Busca erradicar los prejuicios que } \\
\text { están en la base de la estigmatización } \\
\text { social y la discriminación cultural }\end{array}$ & $\begin{array}{l}\text { - Busca erradicar los prejuicios que } \\
\text { están en la base de la estigmatización } \\
\text { social y la discriminación cultural }\end{array}$ \\
\hline $\begin{array}{l}\text { - Las políticas interculturales son } \\
\text { acciones transformativas, es decir, } \\
\text { buscan transformar las relaciones de } \\
\text { interculturalidad negativa en } \\
\text { interculturalidad positiva }\end{array}$ & $\begin{array}{l}\text { - Las políticas interculturales son } \\
\text { acciones transformativas, es decir, } \\
\text { buscan transformar las relaciones de } \\
\text { interculturalidad negativa en } \\
\text { interculturalidad positiva }\end{array}$ \\
\hline $\begin{array}{l}\text { - La racionalidad intercultural es } \\
\text { comunicativa que parte de } \\
\text { reconocimiento del otro interlocutor con } \\
\text { quien comparto en situación de dialogo } \\
\text { una comunidad de valores } \\
\text { transculturales }\end{array}$ & $\begin{array}{l}\text { - La racionalidad intercultural es } \\
\text { comunicativa que parte de } \\
\text { reconocimiento del otro interlocutor con } \\
\text { quien comparto en situación de dialogo } \\
\text { una comunidad de valores } \\
\text { transculturales }\end{array}$ \\
\hline
\end{tabular}

${ }^{10}$ Pèro el terme "intercultural" ja expressa l'opció de posar en contacte, des de la tasca educativa. Constituieix un enfocament, un procediment, un procés dinàmico de naturalesa social, en el qual s'impulsa positivament als participants a ser conscients de la seva interdependencia i és també, una filosofía, una política i un pensament que sistematitza la realitat (GONZÁLEZ MEDIEL, p. 81-82).

12 "La ciudad multicultural ya no se basa em um único poder de cultura autóctona. Todos los hombres y mujeres son ciudadanos. Por ello, un proyecto educativo que promueva la participación ciudadana y el respeto mutuo ha de ser por definición intercultural" (p. 81). 
Educação intercultural em movimento: revisitando um conceito a partir do trabalho de investigação em grupo

13 "La educación intercultural produce la transformación del sujeto solo si el marco de referencia para la comunicación es compartido y existe la voluntad de conocimiento y comprensión del otro; sí no lo es, el dialogo intercultural es inexistente" (p. 507).

${ }^{14}$ En la mesura que els referents de la interculturalitat els hem de buscar en les practiques socials i culturals de les minories, un element clau és desenvolupar tota la potencialitat de l'educació intercultural des d'una concepció més crítica de la teoría i pràctica que centri la seva atenció no limitant-se al tractament implícitament patològic i compensatori de la diversitat cultural en pro de l'èxit acadèmic de les minories, sinó posant l' 'emfasi en les qüestions estructurals més àmplies del racisme i en la preocupació de com educar a tot lálumnat, tant el procedent de la majoria com el de grups social i cultural minoritaris, per una societat multicultural (p. 664).

${ }^{15}$ Las competencias interculturales pueden ser recursos valiosos para las personas de la sociedad de acogida: ciudadanía, profesionales, políticos...." (p. 494).

16 "Mejorar las relaciones interculturales incide en la convivencia y cohesión social, desde la simetría, desde la participación social, desde la igualdad de derechos, y también desde la diferencia cultural y el respeto" (p. 665).

\section{Correspondência}

Gilberto Ferreira da Silva - Rua Brasil, 343, casa 25, CEP 92310-150, Bairro Harmonia, Canoas, Rio Grande do Sul, Brasil.

E-mail: gilberto.ferreira65@gmail.com

Recebido em 06 de fevereiro de 2010

Aprovado em 22 de dezembro de 2010 